\title{
Entre Judith Butler en disputa y Deshacer a Judith Butler*
}

\section{Giancarlo Cornejo**}

El nombre de Judith Butler cada vez más parece ser (usado como) un sinónimo de estudios de género, teoría queer, e incluso de activismo queer y (no sin problemas) de feminismo en general. Esta confluencia entre un nombre propio y diversos campos de investigación y de resistencia da cuenta de la merecida importancia de las propuestas de la filósofa estadounidense Judith Butler. Sin duda, sus propuestas han trascendido las fronteras de la academia estadounidense y han sido y son reapropiadas en contextos muy diferentes de los de su producción. Ese mismo "fenómeno nominal" (en tanto relativo a un nombre) no está exento de complicaciones. Como es inevitable las citaciones de este nombre y su obra (o el conjunto de ideas asociadas a ese nombre propio) muchas veces concluyen en el uso de ciertas frases a manera de slogans, es decir frases que intentan resumir la complejidad de las propuestas butlerianas en dos o tres oraciones que normalmente afirman algo sobre la performatividad del género o sobre las parodias y la subversión. Aquí no se trata simplemente de diferenciar entre buenas y malas lecturas de Butler, como si habláramos de buenas y malas copias de (las propuestas) de Butler, sino de reconocer el complejo proceso de migración y traducción de este nombre y de las teorías asociadas a él y sus implicancias en los campos de conocimiento y resistencia que se lo (re)apropian.

"Resenha de SOlEY-BeltRAN, Patrícia e SABSAY, Leticia (editoras). Judith Butler en disputa: Lecturas sobre la performatividad. Barcelona y Madrid, Egales, 2012. Recebida para publicação em 6 de janeiro de 2013, aceita em $1^{\circ}$ de fevereiro de 2013.

** Estudante de doutorado em Retórica na Universidad de California, Berkeley. giancarlofcs@gmail.com 
Es en ese contexto que radica la importancia de la publicación de Judith Butler en disputa: Lecturas sobre la performatividad, editado por Patrícia Soley-Beltran y Leticia Sabsay. Este es un volumen que incluye el trabajo de seis autorxs especializados en la obra de Butler, muchxs de lxs cuales han publicado importantes monografías sobre su obra y algunxs han traducido obras de Butler al español. Las editoras posicionan este libro frente a lo que llaman Butlerofobia y Butlerofilia, dos pasiones supuestamente antagónicas pero igualmente intensas que giran en torno al nombre "Butler". En el texto mismo, las editoras no descartan ninguno de los dos vínculos apasionados, aunque marcan distancia de ellos, pero en la contraportada del libro se puede leer una desidentificación más radical: "Más allá de la Butlerofilia o la Butlerofobia, los ensayos reunidos en este volumen ofrecen una lectura a conciencia de la obra de Judith Butler". Y esa afirmación en cierto sentido es verdadera; es decir, las lecturas que forman parte de este libro, son muy eruditas sobre la obra de Butler y sus influencias intelectuales, así como sobre los debates teóricos en los que se posiciona, y efectivamente esta erudición es gran parte del atractivo del libro en su conjunto. Sin embargo, no quisiera descartar tan rápidamente ni la Butlerofilia ni la Butlerofobia. Esto se debe quizá a que más que un buen lector de Butler, me considero un fan suyo, y en ese sentido no quiero establecer un vínculo de represión y negación con la Butlerofilia, de la que gozo o padezco (dependiendo de donde se posicione la persona que lea estas páginas). Entonces frente al "más allá" de la contraportada prefiero un "entre". Las editoras mismas aprecian esta preposición, "entre", cuando señalan como respuesta a la importancia de la interdisciplinariedad para Butler, que el presente libro está "situado en el espacio del entre" (p. 25). Por supuesto el "entre" también implica riesgos: probablemente uno de los mayores peligros es la inmovilidad y la funcionalidad de los mecanismos de poder hegemónicos del "punto medio". No obstante, creo que el "entre" al que apelo, como las editoras lo hacen, es una forma de problematizar pertenencias naturalizadas $y$ verdades que a paso de repeticiones violentas han olvidado su 
pasado menos certero. Algo que hace atractivo a la preposición "entre" es que implica espacios que no puede nombrar, que los nombres que van antes y después de dicha preposición no pueden describir ni contener completamente todas sus posibilidades. Además el "entre" explicita sus ejercicios de exclusión, no requiere esconderlos. La misma Judith Butler reivindica la importancia del "entre". Ello se hace más palpable en su giro de la performatividad a la vulnerabilidad (giro que concentra la atención de varixs autores de este libro). La performatividad afirma la riqueza de todo lo que hay entre las posiciones heteronormativas idealizadas de masculinidad y feminidad heterosexual. Y explorando la vulnerabilidad humana, Butler postula una noción de subjetividad que renuncia a cualquier tipo de voluntarismo individualista y que apuesta por su esencial carácter social. El sujeto butleriano vive entre otrxs, y su vida sólo puede ser por la de otrxs.

Esta defensa del "entre" que estoy ensayando no necesita (re)negar (de) su carácter excluyente. Es decir, aunque un "entre" plantea vínculos, inevitablemente también produce límites y fronteras. Por ejemplo, Sabsay y Soley-Beltran plantean con razón que su libro es uno de los que responde al llamado de la interdisciplinariedad, el entre disciplinas, que plantea Butler. Y en efecto, este importante libro se nutre de diversas tradiciones teóricas e interviene en distintos debates que a su vez se asientan en diferentes disciplinas académicas, y sin duda será leído por personas con diferentes pertenencias disciplinarias. No obstante, ambas editoras y Lídia Puigvert son sociólogas de formación, mientras que lxs otrxs tres autores (Pablo Pérez Navarro, Elvira Burgos Díaz y Jesús González Fisac) son filósofxs. Esta interdisciplinariedad que reclama el libro se asienta sobre un "entre", el entre la sociología y la filosofía. No quiero restarle importancia a este hecho, ya que la acogida y recepción que la obra de Butler y su nombre han tenido, y tienen en las ciencias sociales en español (sobre todo en América Latina) quizá tengan cierta relación con la fuerza gravitacional que el mismo nombre y obra tienen en los departamentos de humanidades de muchas universidades de Estados Unidos. Es decir, en este proceso 
migratorio del nombre Butler y de su obra no sólo ha cambiado la procedencia geográfica y étnica de sus lectorxs, sino también las pertenencias disciplinarias y los posicionamientos teóricos de las audiencias butlerianas cada vez más difíciles de prever.

Si Sabsay y Soley-Beltran aprecian el "entre" de la interdisciplinariedad, no pasa lo mismo, por lo menos en el caso de Sabsay, con el "entre" de la interseccionalidad. De hecho en "De sujetos performativos, psicoanálisis y visiones constructivistas" Sabsay agudamente afirma que "el afamado trinomio raza/clase/género se torna cuestionable cuando la articulación de los elementos se lee en términos de "sumatoria" de diferencias, vale decir, como "ejes diferenciadores" que, aun intersectándose unos a otros, continúan manteniendo su autonomía y su propia lógica de identidad (p. 147). Sabsay critica una postura que se ha naturalizado en el feminismo y en los movimientos sexuales progresistas, una postura que plantea que los "entre" no son problemáticos, o que ha tomado por sentada la relativa equivalencia de los nombres que van antes y después de la mencionada preposición. Sabsay advierte que "cada uno de estos ejes de dominación - la clase, el género, la raza - corresponden a unas tradiciones teóricas particulares, cuyas concepciones sobre el antagonismo social difícilmente puedan ser articuladas como mera suma de "diferencias'” (p. 148). De acuerdo con Sabsay el problema del "entre" de la interseccionalidad es la manera ahistórica, universalista y esencialista que borra las diferentes trayectorias de las también diferentes matrices de poder. Una de sus más importantes implicancias es quizá una afirmación de ciertos límites en las teorías de Butler. En cierto sentido, Sabsay implícitamente acepta que es probable que el marco conceptual de la performatividad de Butler sea más útil para analizar las matrices de poder del género y la sexualidad, y no (tanto) así otras matrices de poder. Sospecha más que justificada cuando se toma en cuenta que sus libros merecidamente más famosos y ahora clásicos contemporáneos, El género en disputa (2007) y Cuerpos que importan (2002), exploran el género y la sexualidad. Esta afirmación de límites (que no tienen que ser inmóviles) no niega 
en nada la radicalidad de las propuestas de Butler. De hecho, Sabsay y Soley-Beltran inician su texto afirmando que "Judith Butler trabaja para la transformación social desde la filosofía" (p. 9). Esta es una afirmación que comparto totalmente. Y parte de este constante trabajo en pro de transformaciones sociales implica reconocer límites. El "entre" de las potencialidades y los límites es uno muy importante.

Como debe ya de ser evidente, mi lectura del texto editado por Sabsay y Soley-Beltran intenta explorar el espacio entre sus posibilidades y límites. Es por ello que estoy leyendo dicho libro en sus márgenes, entre sus líneas. Ambas editoras señalan: "Performatividad, género y lenguaje dibujan así tres posibles vectores de lectura" (p. 19). Los seis capítulos que componen el libro centran sus miradas en esos elementos. Es decir sus lecturas se mueven entre esos vectores, que además la propia Butler privilegia en su obra. Las editoras además reconocen que puede haber y hay muchos otros vectores de lectura, pero también se clausuran otros. Insisto que este proceso de exclusión es inevitable, pero sí se puede aspirar a hacerlo visible (para transformarlo). Es así que me pregunto por el lugar de la raza, otro importante y diferente matriz de poder, en esta colección. A primera vista la "raza" es una categoría marginal en Judith Butler en disputa, y se podría afirmar lo mismo de la obra de Judith Butler, quizá con excepción de sus más recientes trabajos. Butler comparte (críticamente) el privilegio analítico de categorías como sexo, género o sexualidad con muchos feminismos y movimientos sexuales progresistas. Entonces, no es excepcional sino sintomática la ausencia de la problematización de la "raza" en buena parte de la recepción que la obra de Butler ha tenido en el contexto hispano. Tampoco esta ausencia es una característica particular de este libro. Y su ausencia no es total, la "raza" habita en los márgenes del libro. Por ejemplo, en "No-body is perfect.' Transexualidad y performatividad de género" Patrícia SoleyBeltran hace un análisis de los sentidos de pertenencia de ciertas personas transexuales en España e Inglaterra; contribuyendo así con argumentos bastante importantes para los movimientos por la 
despatologización de las identidades trans. No obstante, o talvez por ello mismo, las únicas referencias a la raza aparecen en su texto citando a uno de sus informantes quien señala que "No sé/es como si... te gusta ser morena y andases rubia" (p. 66), o cuando la autora diferencia los usos de la categoría "travesti" de "transgénero": "Las travestis en su mayoría trabajadoras sexuales de origen sudamericano, mostraban una exuberante apariencia femenina, a menudo en espacios públicos urbanos, mientras que mantenían sus genitales masculinos intactos" (p. 90). Señalo estas referencias sin ningún afán de deslegitimar este trabajo, al que reconozco sus méritos y respeto. Lo hago porque en mi lectura quiero explorar las posibilidades teóricas y políticas de las teorías butlerianas de la performatividad en contextos como los de América Latina. Sospecho que reconociendo lo que plantea Sabsay, es decir que no se pueden presumir como equivalentes diferentes matrices de poder, lo que implica no asumirlas tampoco como mutuamente excluyentes o como sumatorias de elementos particulares, es importante articular las formas en que diferentes matrices de poder tienen efectos que coinciden en su violencia contra determinadas comunidades y subjetividades.

Por supuesto que Judith Butler jamás negaría la importancia de articulaciones solidarias e internacionales que luchen contra los poderes hegemónicos que precarizan determinadas vidas humanas. De hecho, su obra en conjunto apunta a esta clase de políticas, pero su obra es también una invitación a realizar el trabajo académico-político que posibilite esta clase de alianzas por democracia radical. Es decir, aun cuando los libros más importantes de Butler son en torno al género y la sexualidad, éstos son una provocadora invitación para continuar actuando y pensando críticamente. Ella no ofrece un modelo (el de la performatividad) que se puede aplicar a cualquier matriz de poder de manera simple. Es a eso a lo que creo que apunta Sabsay. Y es por ello también que creo importante que el último capítulo del libro sea "Reflexiones en torno a la teoría feminista y las transformaciones sociales" de Lídia Puigvert. En ese bello capítulo se producen diálogos entre voces diferentes de mujeres también 
diferentes, y una de ellas es Butler. Allí se apuesta por un diálogo abierto con audiencias que Butler no podía prever, y al mismo tiempo Butler es construida como parte de una audiencia internacional sobre las teorías de la dominación y las estrategias de resistencia de mujeres de comunidades marginadas y excluidas. Al cerrar con ese capítulo y con una entrevista a Butler, Judith Butler en disputa nos plantea un reto: El de seguir disputando no sólo a Judith Butler, sino también a las diferentes matrices de poder $y$ sus efectos conjuntos.

Ahora, y para finalizar, quiero volver al nombre de Butler. Como afirma Denise Riley (2005) los nombres propios que supuestamente son la prueba irrefutable de nuestra individualidad, son en realidad eminentemente sociales y nunca nos pertenecen del todo. Tienen una vida que no está determinada por la vida de nuestro cuerpo. Y Judith Butler lo sabe muy bien. En la entrevista que le concedió a las editoras afirma: "dejo que mi nombre propio tenga una vida diferente de la que yo, de hecho, vivo" (p. 234). Y es también por esa no coincidencia entre Judith Butler y su nombre que creo que ni la Butlerofilia ni la Butlerofobia deben descartarse tan ligeramente. Aunque tras muchas formas de Butlerofilia se esconda un imperialismo académico-político innegable, o tras ciertas Butlerofobias no haya más que homofobia, transfobia y misoginia, creo que es posible que ambas posiciones no sean solo eso. Es decir, talvez ciertas Butlerofilias pueden movilizar políticamente a individuos y colectivos para resistir determinadas normas, o incluso para reclamar para sí ciertas formas más habitables de poder. Y quizá ciertas Butlerofobias puedan ser estratégicamente útiles para no reducir todos los estudios de género y sexualidades a la performatividad, o para reivindicar producciones teóricas del Sur Global. Es también por ello que creo que la sugerente reapropiación del Género en disputa que hacen las editoras al titular su libro Judith Butler en disputa, puede ser respondida por ciertxs lectores con una reapropiación de Deshacer el género (2006), y postular así "Deshacer a Judith Butler". Butler no rechaza el género ni su pertinencia política o teórica, pero sí busca darle nuevas formas a 
506 Entre Judith Butler en disputa y Deshacer a Judith Butler"

dicha categoría y radicalizar sus potencialidades; además renuncia el fetichizar al género y convertirlo en una deidad. Talvez un movimiento similar es el que el nombre de Judith Butler requiere.

\section{Referencias bibliográficas}

BUTLER, Judith. Cuerpos que importan: Sobre los límites materiales y discursivos del "sexo", Buenos Aires, Paidós, 2002.

. Deshacer el género, Barcelona, Paidós, 2006.

. El Género en disputa: El feminismo y la subversión de la identidad. Barcelona, Paidós, 2007.

RILEY, Denise. Impersonal Passion: Language as Affect. Durham, Duke University Press, 2005. 